\title{
Renal function is associated with one-month and one-year mortality in patients with intracerebral hemorrhage
}

\author{
I-Kuan Wang ${ }^{1}$, Tzung-Hai Yen ${ }^{2}$, Chon-Haw Tsai ${ }^{2}$, Yu Sun ${ }^{2}$, Wei-Lun Chang ${ }^{2}$, Po-Lin \\ Chen $^{2}$, Ta-Chang Lai ${ }^{2}$, Po-Yen Yeh ${ }^{2}$, Cheng-Yu Wei ${ }^{2}$, Cheng-Li Lin ${ }^{2}$, Chi-Yuan Li ${ }^{1}$, \\ Fung-Chang Sung ${ }^{2}$, and Chung Y Hsu ${ }^{2}$ \\ ${ }^{1}$ China Medical University Hospital \\ ${ }^{2}$ Affiliation not available
}

May 28, 2021

\begin{abstract}
Background: This study evaluated short-term (1-month) and long-term (1-year) mortality risks associated with kidney function measured by estimated glomerular filtration rate (eGFR) levels at admission for patients with intracerebral hemorrhage. Methods: From the Taiwan Stroke Registry data, we identified and stratified patients with intracerebral hemorrhage into 5 subgroups by the eGFR levels at admission: [?] 90, 60-89, 30-59, 15-29, and $<15 \mathrm{~mL} / \mathrm{min} / 1.73 \mathrm{~m} 2$ or on dialysis from April 2006 to December 2016. Risks of 1-month mortality and 1-year mortality rates after intracerebral hemorrhage were investigated by the eGFR levels. Results: Both the 1-month mortality and 1-year mortality rates increased as the eGFR level decreased. The 1-month mortality rate was over 5 -fold greater in patients with eGFR $<15 \mathrm{~mL} / \mathrm{min} / 1.73 \mathrm{~m} 2$ or on dialysis than in patients with eGFR levels [?] $90 \mathrm{~mL} / \mathrm{min} / 1.73 \mathrm{~m} 2$ (8.31 versus 1.50 per 1000 person-days), with an adjusted hazard ratio (HR) of 4.59 $[95 \%$ confidence interval $(\mathrm{CI})=2.71-7.78]$. Similarly, the 1-year mortality rate was 7.5 -fold greater in patients with eGFR $<$ $15 \mathrm{~mL} / \mathrm{min} / 1.73 \mathrm{~m} 2$ or on dialysis than in patients with eGFR [?] $90 \mathrm{~mL} / \mathrm{min} / 1.73 \mathrm{~m} 2$, with an adjusted HR of 4.54 (95\% CI 2.95-6.98). Conclusion: The eGFR level can be an indicator of prognosis for patients with intracerebral hemorrhage.
\end{abstract}

Title: Renal function is associated with one-month and one-year mortality in patients with intracerebral hemorrhage

Running title: eGFR and intracerebral hemorrhage

I-Kuan Wang, PhD ${ }^{1,2}$; Tzung-Hai Yen, $\mathrm{PhD}^{3,4}$; Chon-Haw Tsai, $\mathrm{PhD}^{5}$; Yu Sun, $\mathrm{PhD}^{6}$; Wei-Lun Chang, $\mathrm{MD}^{7}$; Po-Lin Chen, $\mathrm{MD}^{8,9}$; Ta-Chang Lai MD ${ }^{10}$; Po-Yen Yeh, MD ${ }^{11}$; Cheng-Yu Wei, MD ${ }^{12}$; Cheng-Li Lin, $\mathrm{MS}^{13}$; Chi-Yuan Li, MD ${ }^{14}$, 15*; Fung-Chang Sung, PhD, MPH ${ }^{16,17 *}$; Chung Y. Hsu, MD, PhD ${ }^{15}$, and Taiwan Stroke Registry Investigators

${ }^{1}$ Department of Internal Medicine, College of Medicine, China Medical University, Taichung, Taiwan

${ }^{2}$ Division of Nephrology, China Medical University Hospital, Taichung, Taiwan

${ }^{3}$ Division of Nephrology, Chang Gung Memorial Hospital, Taipei, Taiwan

${ }^{4}$ Chang Gung University College of Medicine, Taoyuan, Taiwan

${ }^{5}$ Department of Neurology, Show Chwan Memorial Hospital, Changhua County, Taiwan ${ }^{6}$ Neurology, En Chu Kong Hospital, New Taipei City, Taiwan

${ }^{7}$ Department of Neurology, Show Chwan Memorial Hospital, Changhua County, Taiwan

${ }^{6}$ Department of Neurology, College of Medicine, National Cheng Kung University, Tainan, Taiwan 
${ }^{8}$ Neurological Institute, Taichung Veterans General Hospital, Taichung, Taiwan ${ }^{9}$ Department of Neurology, School of Medicine, National Yang-Ming University, Taipei, Taiwan. ${ }^{10}$ Division of Neurology Department of Internal medicine, Cheng Hsin General Hospital, Taipei, Taiwan ${ }^{11}$ Department of Neurology, St. Martin De Porres Hospital, Chiayi , Taiwan ${ }^{12}$ Department of Neurology, Chang Bing Show Chwan Memorial Hospital, Changhua, Taiwan

${ }^{13}$ Management Office for Health Data, China Medical University Hospital, Taichung, Taiwan

${ }^{14}$ Department of Anesthesiology, China Medical University Hospital, Taichung, Taiwan

${ }^{15}$ Graduate Institute of Biomedical Science, China Medical University College of Medicine, Taichung, Taiwan

${ }^{16}$ Department of Health Services Administration, China Medical University College of Public Health, Taichung 404, Taiwan

${ }^{17}$ Department of Food Nutrition and Health Biotechnology, Asia University, Taichung 413, Taiwan

Corresponding author:

Fung-Chang Sung, PhD, MPH

Professor

Department of Health Services Administration, China Medical University College of Public Health, Taichung 404, Taiwan

91 Hsueh Shih Road

Taichung 404, Taiwan

Tel: 886-4-2205-4070

Fax: 886-4-2201-9901

E-mail: fcsung1008@yahoo.com

*Equal distribution

Word count: 201 words in the Abstract, 1981 words in the text; 3 tables, 3 figures, and 26 references, 2 supplementary tables

Acknowledgements : This work is supported in part by Ministry of Health and Welfare, Taiwan (MOHW109-TDU-B-212-114004), Children's Hospital of China Medical University (DMR-108-045), China Medical University Hospital (DMR-110-037 and DMR-109-175), Academia Sinica Stroke Biosignature Project (BM10701010021), MOST Clinical Trial Consortium for Stroke (MOST 107-2321-B-039 -004), TsengLien Lin Foundation, Taichung, Taiwan, and Katsuzo and Kiyo Aoshima Memorial Funds, Japan.

Author Contributors: I-Kuan Wang, Tzung-Hai Yen, Chon-Haw Tsai, Yu Sun, Wei-Lun Chang, Po-Lin Chen, Ta-Chang Lai, Po-Yen Yeh, Cheng-Yu Wei designed the study and drafted the manuscript. ChengLi Lin conducted the statistical analysis. Chi-Yuan Li, Chung Y. Hsu, and Fung-Chang Sung revised the manuscript.

Key words: estimated glomerular filtration rate, intracerebral hemorrhage, mortality, predictor, renal function

Title: Renal function is associated with one-month and one-year mortality in patients with intracerebral hemorrhage

\section{Abstract}

Background: This study evaluated short-term (1-month) and long-term (1-year) mortality risks associated with kidney function measured by estimated glomerular filtration rate (eGFR) levels at admission for patients 
with intracerebral hemorrhage. Methods:From the Taiwan Stroke Registry data, we identified and stratified patients with intracerebral hemorrhage into 5 subgroups by the eGFR levels at admission: [?] 90, 60-89, $30-59,15-29$, and $<15 \mathrm{~mL} / \mathrm{min} / 1.73 \mathrm{~m}^{2}$ or on dialysis from April 2006 to December 2016. Risks of 1month mortality and 1-year mortality rates after intracerebral hemorrhage were investigated by the eGFR levels.Results: Both the 1-month mortality and 1-year mortality rates increased as the eGFR level decreased. The 1-month mortality rate was over 5 -fold greater in patients with eGFR $<15 \mathrm{~mL} / \mathrm{min} / 1.73 \mathrm{~m}^{2}$ or on dialysis than in patients with eGFR levels [?] $90 \mathrm{~mL} / \mathrm{min} / 1.73 \mathrm{~m}^{2}$ (8.31 versus 1.50 per 1000 person-days), with an adjusted hazard ratio (HR) of 4.59 [95\% confidence interval $(\mathrm{CI})=2.71-7.78]$. Similarly, the 1-year mortality rate was 7.5 -fold greater in patients with eGFR $<15 \mathrm{~mL} / \mathrm{min} / 1.73 \mathrm{~m}^{2}$ or on dialysis than in patients with eGFR [?] $90 \mathrm{~mL} / \mathrm{min} / 1.73 \mathrm{~m} 2$, with an adjusted HR of 4.54 (95\% CI 2.95-6.98).Conclusion: The eGFR level can be an indicator of prognosis for patients with intracerebral hemorrhage.

\section{What's already known about this topic?}

Renal dysfunction is one of the risk factors for the development of cardiovascular disease, including stroke, and death. It is uncertain whether renal dysfunction could be a poor prognostic factor in patients with intracerebral hemorrhage.

\section{What does this article add?}

The eGFR level could be used as an early biomarker to identify high mortality risks for patients with intracerebral hemorrhage. Patients with intracerebral hemorrhage and a low eGFR deserve more clinical attention and closer follow-up monitoring.

\section{Introduction}

Stroke is one of major causes of death and disability worldwide and it has become the fourth leading cause of death in the US. ${ }^{1}$ The impacts of stroke on quality of life, productivity, and health care costs are tremendous. Because of the high social and financial burden, it is important to study the prognostic factors after stroke.

Renal dysfunction is one of the risk factors for the development of cardiovascular disease, including stroke, and death. ${ }^{2-5}$ On the other hand, renal function impairment is highly prevalent in patients with stroke. Up to $50 \%$ of stroke patients have preexisting renal dysfunction. ${ }^{6,7}$ Previous studies have shown that the renal dysfunction predicts the risks of both mortality and new cardiovascular events in patient with stroke. ${ }^{7-9}$ There is a graded relationship between renal dysfunction and cardiovascular outcomes, including deaths in these patients. In our previous studies, we also found that the estimated glomerular filtration rate (eGFR) is associated with risks of both 1-month and 1-year mortality and of recurrence in patients with acute ischemic stroke. ${ }^{10,11}$ Intracerebral hemorrhage is a more devastating stroke than ischemic stroke, carrying a higher risk of subsequent morbidity and mortality. ${ }^{12,13}$ Renal dysfunction has been found to be a poor prognostic factor in patients with intracerebral hemorrhage. ${ }^{14-18}$ However, other studies failed to show renal dysfunction as a significant predictor of mortality in patients with intracerebral hemorrhage. ${ }^{8,19}$ Because of previous inconsistent results, this study investigated whether the risks of 1-month and 1-year mortality are associated with eGFR levels in patients with intracerebral hemorrhage using the Taiwan Stroke Registry (TSR) database.

\section{Methods}

\section{Data source}

TSR, launched in 2006, is a multi-center stroke registry system with participation of 38 hospitals (16 medical centers, 20 regional hospitals, and 2 local hospitals) in Taiwan ${ }^{20}$. Trained personals at participation hospitals were in charge of registry tasks and the follow-up data collection. The registration data contained demographic profiles, information on National Institute of Health Stroke Scale (NIHSS), hospitalization records, and discharge information. Telephone contacts were performed at 1, 3, 6, and 12 months after stroke to collect follow-up information, including deaths. The informed consents were obtained from all patients before being included in the registry program. This study was performed in compliance with guidelines of the 
Declaration of Helsinki and approved by the Institutional Review Board [CMUH102-REC1-086 (CR3)].

\section{Study Population}

Among a total of 105,994 stroke patients registered from 2006 to 2016 in the TSR, 15,031 were patients with intracerebral hemorrhage (Figure 1). Patients with intracerebral hemorrhage caused by trauma or brain tumors were not registered in this database. We excluded patients younger than 18 years old, and patients without information on dialysis status, body mass index (BMI), systolic blood pressure levels, hemoglobin $(\mathrm{Hb})$ levels, serum cholesterol levels, or serum creatinine levels. Patients who died during hospitalization were not excluded. A total of 4,036 hemorrhagic stroke patients were included in this study and divided into five subgroups by the level of estimated glomerular filtration rate (eGFR): [?] $90 \mathrm{ml} / \mathrm{min} / 1.73 \mathrm{~m}^{2}$, $60-89 \mathrm{ml} / \mathrm{min} / 1.73 \mathrm{~m}^{2}, 30-59 \mathrm{ml} / \mathrm{min} / 1.73 \mathrm{~m}^{2}, 15-29 \mathrm{ml} / \mathrm{min} / 1.73 \mathrm{~m}^{2}$, and $<15 \mathrm{ml} / \mathrm{min} / 1.73 \mathrm{~m}^{2}$ or on dialysis. The eGFR was calculated by the Chronic Kidney Disease Epidemiology Collaboration (CKD-EPI) equation for each non-dialysis patient ${ }^{21}$. The CKD-EPI equation, expressed as a single equation, is GFR $=141 \times \min (\mathrm{Scr} / x, 1)^{\alpha} \times \max (\mathrm{Scr} / x, 1)^{-1.209} \times 0.993^{\text {Age }} \times 1.018$ [if female] $\times 1.159$ [if black], where Scr is serum creatinine, $x$ is 0.7 for females and 0.9 for males, $\alpha$ is -0.329 for females and -0.411 for males, min indicates the minimum of Scr/xor 1, and max indicates the maximum of Scr/ $x$ or 1 . The etiologies of intracerebral hemorrhage were classified into hypertension and non-hypertensive causes. One-month and one-year mortality rates after intracerebral hemorrhage were evaluated by the eGFR levels.

\section{Statistical analysis}

Distributions of baseline characteristics were compared among five eGFR groups, including sex, age, BMI, smoking, comorbidity, clinical characteristics, medication use prior to admission, and the 1-month, and 1-year mortality rates. Data of continuous variables were expressed as median and 25 th percentile to 75 th percentile and examined using the Kruskal-Wallis test for continuous variables that were not normally distributed. Categorical variables were expressed as frequencies and examined using the Chi-square test.

The cumulative incidence curves of mortality were computed for the 5 subgroups of eGFR levels by the Kaplan-Meier method and tested using the log-rank test. The 1-month and 1-year mortality rates (per 1000 person-days) after intracerebral hemorrhagic were calculated by the eGFR levels. We further used the Cox proportional hazards regression analysis to estimate the hazard ratio (HR) of mortality and $95 \%$ confidence interval (CI) associated with eGFR levels at admission for patients with intracerebral hemorrhage, using patients with eGFR [?] $90 \mathrm{~mL} / \mathrm{min} / 1.73 \mathrm{~m}^{2}$ as references. We also used the receiver operating characteristic (ROC) curve to assess the predictive performance of eGFR levels with regard to one-month mortality and oneyear mortality after intracerebral hemorrhage. All statistical analyses were performed using SAS statistical software, version 9.4 (SAS Institute Inc., Cary, NC). Statistical significance was defined using two-tailed tests $(\mathrm{P}<0.05)$.

\section{Results}

Of the 4,036 patients with intracerebral hemorrhage, 2887 (71.5\%) had eGFR $<90 \mathrm{~mL} / \mathrm{min} / 1.73 \mathrm{~m}^{2}$ (Figure 1). $169(4.2 \%)$ patients were in the group with eGFR $<15 \mathrm{~mL} / \mathrm{min} / 1.73 \mathrm{~m}^{2}$ or on dialysis.

Table 1 shows that more than two third $(\mathrm{n}=2677)$ of the patients with intracerebral hemorrhage were men. With a median age of 61.4 years, the age of study population increased as the eGFR level decreased. In general, prevalence rates of comorbidities, scores of NIHSS, systolic blood pressure and medication use prior to admission tended to be higher in groups with lower eGFR, whereas Hb levels were lower in groups with lower eGFR. Of the baseline comorbidities in all study patients, hypertension was the most prevalent comorbidity $(86.6 \%)$, followed by diabetes mellitus, previous stroke, ischemic heart disease, atrial fibrillation, and congestive heart failure (1.21\%).

The cumulative incidence rates of overall mortality in one year in patients with intracerebral hemorrhage increased as the eGFR level declined $(\mathrm{P}<0.001)$. The proportional mortality rate was $38 \%$ greater in those with an eGFR of $<15 \mathrm{ml} / \mathrm{min} / 1.73 \mathrm{~m}^{2}$ than in those with eGFR levels [?] $90 \mathrm{~mL} / \mathrm{min} / 1.73 \mathrm{~m}^{2}$ (Figure 2). 
Both one-month mortality $(\mathrm{N}=258)$ and one-year mortality $(\mathrm{N}=394)$ rates of patients with intracerebral hemorrhage were negatively associated with their eGFR levels at admission (Table 2 and 3). The one-month mortality rate increased as the eGFR levels decreased, from 1.5 per 1000 person-days in patients with eGFR levels [?] 90 to 8.31 per 1000 person-days in patients with eGFR levels $<15 \mathrm{ml} / \mathrm{min} / 1.73 \mathrm{~m}^{2}$. The adjusted HR was $4.59(95 \% \mathrm{CI}=2.71,7.78)$ for patients with eGFR levels $<15 \mathrm{ml} / \mathrm{min} / 1.73 \mathrm{~m} 2$ compared to those with eGFR levels [?] $90 \mathrm{~mL} / \mathrm{min} / 1.73 \mathrm{~m}^{2}$. The corresponding adjusted HR of one-year mortality increased to $4.54(95 \% \mathrm{CI}=2.59,6.98)$ for those with eGFR levels $<15 \mathrm{ml} / \mathrm{min} / 1.73 \mathrm{~m}^{2}$. Other risk factors associated with one-year mortality after intracerebral hemorrhage included female, age, non-hypertensive cause, atrial fibrillation, systolic blood pressure, NIHSS score at admission, warfarin use prior to admission (Table S1).

The area under the ROC curves for the eGFR level in predicting one-month mortality, and one-year mortality were 0.64 (Figure 3A), and 0.66 (Figure 3B) in patients with intracerebral hemorrhage, respectively.

\section{Discussion}

Our study found that there was an independent graded association between eGFR levels and risks of both 1-month and 1-year mortalities in patients with intracerebral hemorrhage after adjusting age, stroke severity and comorbidities. The risk of mortality increased as the eGFR declined.

Renal dysfunction is a known independent risk factor for mortality after stroke. A Scotland study followed 2042 stroke patients for 7 -year and found that reduced creatinine clearance $(<51.27 \mathrm{ml} / \mathrm{min})$ and raised serum creatinine ([?]1.35 mg/dL) could predict deaths in patients with acute stroke ${ }^{8}$. But, the study failed to show renal function as a significant predictor of mortality in hemorrhagic stroke because of small size of fatal events. ${ }^{8}$ A recent study from Taiwan found renal function could play a highly significant role in predicting mortality among ischemic stroke patients. ${ }^{11}$ An Israel study assessed risk factors associated with deaths for patients with acute stroke during one-year follow-up. ${ }^{7}$ Results demonstrated that eGFR was a strong predictor of mortality and poor functional outcomes, such as nursing home dwelling and Barthel index [?]75. Hao et al. reported that an eGFR of $<60 \mathrm{ml} / \mathrm{min} / 1.73 \mathrm{~m}^{2}$ was a strong predictor of mortality and disability for hemorrhagic stroke but not for ischemic stroke. ${ }^{18}$ Molshatzki revealed that presence of moderate to severe reduction of eGFR $\left(<45 \mathrm{ml} / \mathrm{min} / 1.73 \mathrm{~m}^{2}\right)$ was associated larger, lobar hematomas and hence higher one-year mortality in patients with intracerebral hemorrhage. ${ }^{16}$ Data from the GET WITH The Guidelines-Stroke (GWTG-Stroke) program showed that, after intracerebral hemorrhage, patients had an increasing risk of in-hospital mortality with declining eGFR. ${ }^{17}$ On the contrary, a study analyzing China National Stroke Registry found that low eGFR $\left(<45 \mathrm{ml} / \mathrm{min} / 1.73 \mathrm{~m}^{2}\right)$ was independently associated with an increased risk of mortality in diabetic patients with ischemic events, but not in those with hemorrhagic stroke $^{19}$. Our study focused on patients with intracerebral hemorrhage and found that eGFR levels could predict the risk of mortality in a graded relationship. This finding both confirms the results of previous studies and provides new information on the mortality prediction for intracerebral hemorrhage.

Decline in renal function is associated with anemia, increased oxidative stress, abnormal apolipoprotein levels, inflammation, calcium-phosphate derangement, elevated uremic toxins, hypercoagulability, and impaired immunity. ${ }^{4,22-24}$ All these factors may contribute to the increased risks of adverse outcomes such as cardiovascular events, infection episodes, and deaths. These mechanisms may explain the graded association between impaired renal function and the risk of death in patients with hemorrhagic stroke. Our data also showed that most of the baseline comorbidities were reversely associated with eGFR levels, indicating that patients with low eGFR levels were more critically ill. In addition, patients with a lower eGFR also had a higher NIHSS score, indicating that impaired renal function could be associated with stroke severity.

The strength of this study is using a large sample size from stroke registry data with a representative group of stroke patients in Taiwan. Thus, we could estimate the real world prognosis of patients with intracerebral hemorrhage in Taiwan. In addition, we used the CKD-EPI equation to estimate the eGFR as it is better than the MDRD equation for Asian people. ${ }^{25}$ However, there are several limitations in this study. First, there is no data regarding to the quantity of proteinuria in the TSR database. We were unable to evaluate eGFR and proteinuria simultaneously. Proteinuria is an important and independent risk factor for cardiovascular 
disease. ${ }^{5,26}$ Second, serum creatinine was measured and recorded once at the time of admission and it was confounded by acute illness. Therefore, it is difficult to determine the chronicity of renal dysfunction. Furthermore, some patients were excluded from analysis because of missing information. The precision of measurement might be affected. However, the demographic characteristics, the prevalence of comorbidities, the values of laboratory data, and the percentage of people using medication prior to admission were similar between the selected and excluded patients (Table S2). Moreover, although data on hematoma volume, location, and the type of intracerebral hemorrhage were unavailable in this database, the NIHSS score as stroke severity was adjusted in the multivariate analysis. In addition, the use of direct oral anticoagulant was not recorded in this database. This is a limitation for external validity.

\section{Conclusion}

There is an independent graded negative association between levels of eGFR levels at admission and mortality in patients with intracerebral hemorrhage. Patients with intracerebral hemorrhage and eGFR levels $<15 \mathrm{ml} / \mathrm{min} / 1.73 \mathrm{~m}^{2}$ have a near 4 -fold increased hazard of deaths compared to those with intracerebral hemorrhage and eGFR levels [?] $90 \mathrm{~mL} / \mathrm{min} / 1.73 \mathrm{~m}^{2}$. The eGFR level could be used as an early biomarker to identify high mortality risks for patients with intracerebral hemorrhage. Patients with intracerebral hemorrhage and a low eGFR deserve more clinical attention and closer follow-up monitoring.

\section{Disclosures}

None declared

\section{References}

1. Towfighi A, Saver JL. Stroke declines from third to fourth leading cause of death in the United States: historical perspective and challenges ahead. Stroke. 2011;42(8):2351-2355.

2. Foley RN, Murray AM, Li S, et al. Chronic kidney disease and the risk for cardiovascular disease, renal replacement, and death in the United States Medicare population, 1998 to 1999. J Am Soc Nephrol.2005;16(2):489-495.

3. Weiner DE, Tighiouart H, Amin MG, et al. Chronic kidney disease as a risk factor for cardiovascular disease and all-cause mortality: a pooled analysis of community-based studies. $J$ Am Soc Nephrol.2004;15(5):1307-1315.

4. Go AS, Chertow GM, Fan D, McCulloch CE, Hsu CY. Chronic kidney disease and the risks of death, cardiovascular events, and hospitalization. N Engl J Med. 2004;351(13):1296-1305.

5. McCullough PA, Li S, Jurkovitz CT, et al. CKD and cardiovascular disease in screened high-risk volunteer and general populations: the Kidney Early Evaluation Program (KEEP) and National Health and Nutrition Examination Survey (NHANES) 1999-2004. Am J Kidney Dis. 2008;51(4 Suppl 2):S38-45.

6. El Husseini N, Fonarow GC, Smith EE, et al. Renal Dysfunction Is Associated With Poststroke Discharge Disposition and In-Hospital Mortality: Findings From Get With The Guidelines-Stroke. Stroke.2017;48(2):327-334.

7. Yahalom G, Schwartz R, Schwammenthal Y, et al. Chronic kidney disease and clinical outcome in patients with acute stroke. Stroke.2009;40(4):1296-1303.

8. MacWalter RS, Wong SY, Wong KY, et al. Does renal dysfunction predict mortality after acute stroke? A 7-year follow-up study. Stroke.2002;33(6):1630-1635.

9. Tsagalis G, Akrivos T, Alevizaki M, et al. Renal dysfunction in acute stroke: an independent predictor of long-term all combined vascular events and overall mortality. Nephrol Dial Transplant.2009;24(1):194-200.

10. Wang IK, Lien LM, Lee JT, et al. Renal dysfunction increases the risk of recurrent stroke in patients with acute ischemic stroke. Atherosclerosis. 2018;277:15-20. 
11. Wang IK, Liu CH, Yen TH, et al. Renal function is associated with 1-month and 1-year mortality in patients with ischemic stroke.Atherosclerosis. 2018;269:288-293.

12. Wong KS. Risk factors for early death in acute ischemic stroke and intracerebral hemorrhage: A prospective hospital-based study in Asia. Asian Acute Stroke Advisory Panel. Stroke. 1999;30(11):23262330.

13. Yoneda Y, Okuda S, Hamada R, et al. Hospital cost of ischemic stroke and intracerebral hemorrhage in Japanese stroke centers. Health Policy. 2005;73(2):202-211.

14. Khatri R, Afzal MR, Qureshi MA, Maud A, Huanyu D, Jose Rodriguez G. Pre-Existing Renal Failure Increases In-Hospital Mortality in Patients with Intracerebral Hemorrhage. J Stroke Cerebrovasc Dis.2019;28(2):237-242.

15. Kim JK, Shin JJ, Park SK, Hwang YS, Kim TH, Shin HS. Prognostic factors and clinical outcomes of acute intracerebral hemorrhage in patients with chronic kidney disease. $J$ Korean Neurosurg Soc.2013;54(4):296-301.

16. Molshatzki N, Orion D, Tsabari R, et al. Chronic kidney disease in patients with acute intracerebral hemorrhage: association with large hematoma volume and poor outcome. Cerebrovasc Dis.2011;31(3):271277.

17. Ovbiagele B, Schwamm LH, Smith EE, et al. Hospitalized hemorrhagic stroke patients with renal insufficiency: clinical characteristics, care patterns, and outcomes. J Stroke Cerebrovasc Dis.2014;23(9):22652273 .

18. Hao Z, Wu B, Lin S, et al. Association between renal function and clinical outcome in patients with acute stroke. Eur Neurol.2010;63(4):237-242.

19. Luo Y, Wang X, Wang Y, et al. Association of glomerular filtration rate with outcomes of acute stroke in type 2 diabetic patients: results from the China National Stroke Registry. Diabetes Care.2014;37(1):173-179.

20. Unites States Renal data System: USRDS 2013 Annual Data Report.

21. Levey AS, Stevens LA, Schmid CH, et al. A new equation to estimate glomerular filtration rate. Ann Intern Med. 2009;150(9):604-612.

22. Hauser AB, Stinghen AE, Kato S, et al. Characteristics and causes of immune dysfunction related to uremia and dialysis. Perit Dial Int. 2008;28 Suppl 3:S183-187.

23. McCullough PA, Jurkovitz CT, Pergola PE, et al. Independent components of chronic kidney disease as a cardiovascular risk state: results from the Kidney Early Evaluation Program (KEEP). Arch Intern Med. 2007;167(11):1122-1129.

24. Sozio SM, Armstrong PA, Coresh J, et al. Cerebrovascular disease incidence, characteristics, and outcomes in patients initiating dialysis: the choices for healthy outcomes in caring for ESRD (CHOICE) study. Am J Kidney Dis. 2009;54(3):468-477.

25. Matsushita K, Mahmoodi BK, Woodward M, et al. Comparison of risk prediction using the CKD-EPI equation and the MDRD study equation for estimated glomerular filtration rate. JAMA.2012;307(18):19411951.

26. Agrawal V, Marinescu V, Agarwal M, McCullough PA. Cardiovascular implications of proteinuria: an indicator of chronic kidney disease.Nat Rev Cardiol. 2009;6(4):301-311.

\section{Legends}

Figure 1. Flow chart for identifying patients with intracerebral hemorrhage by eGFR levels at admission 
Figure 2. The cumulative incidence of mortalities after intracerebral hemorrhagic by eGFR levels at admission

Figure 3. The area under the receiver operating characteristic curves for eGFR levels at admission in predicting one-month mortality (A) and one-year mortality (B) in patients with intracerebral hemorrhage.

Table 1. Baseline characteristics of patients with intracerebral hemorrhage at admission by eGFR levels at admission

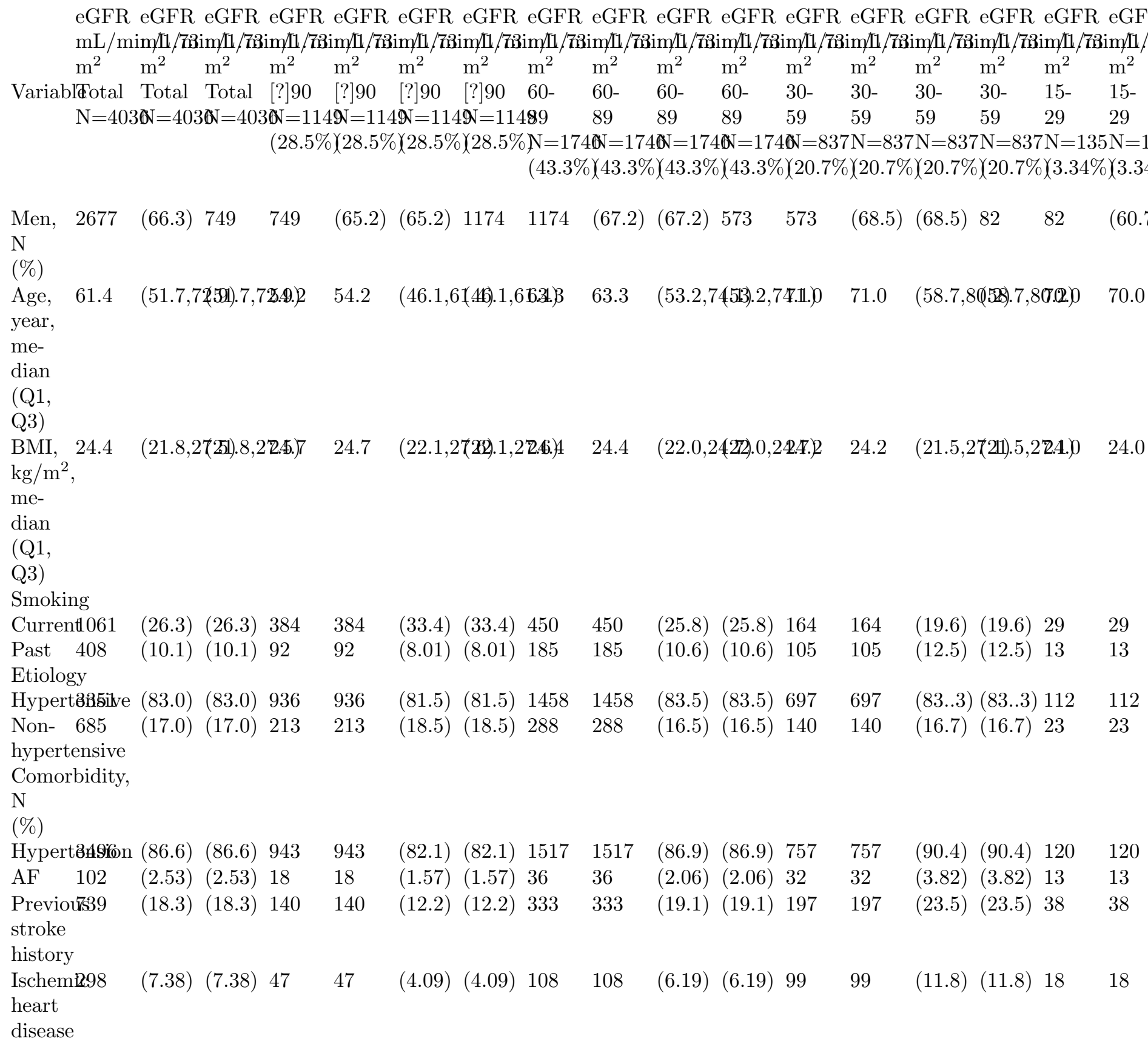




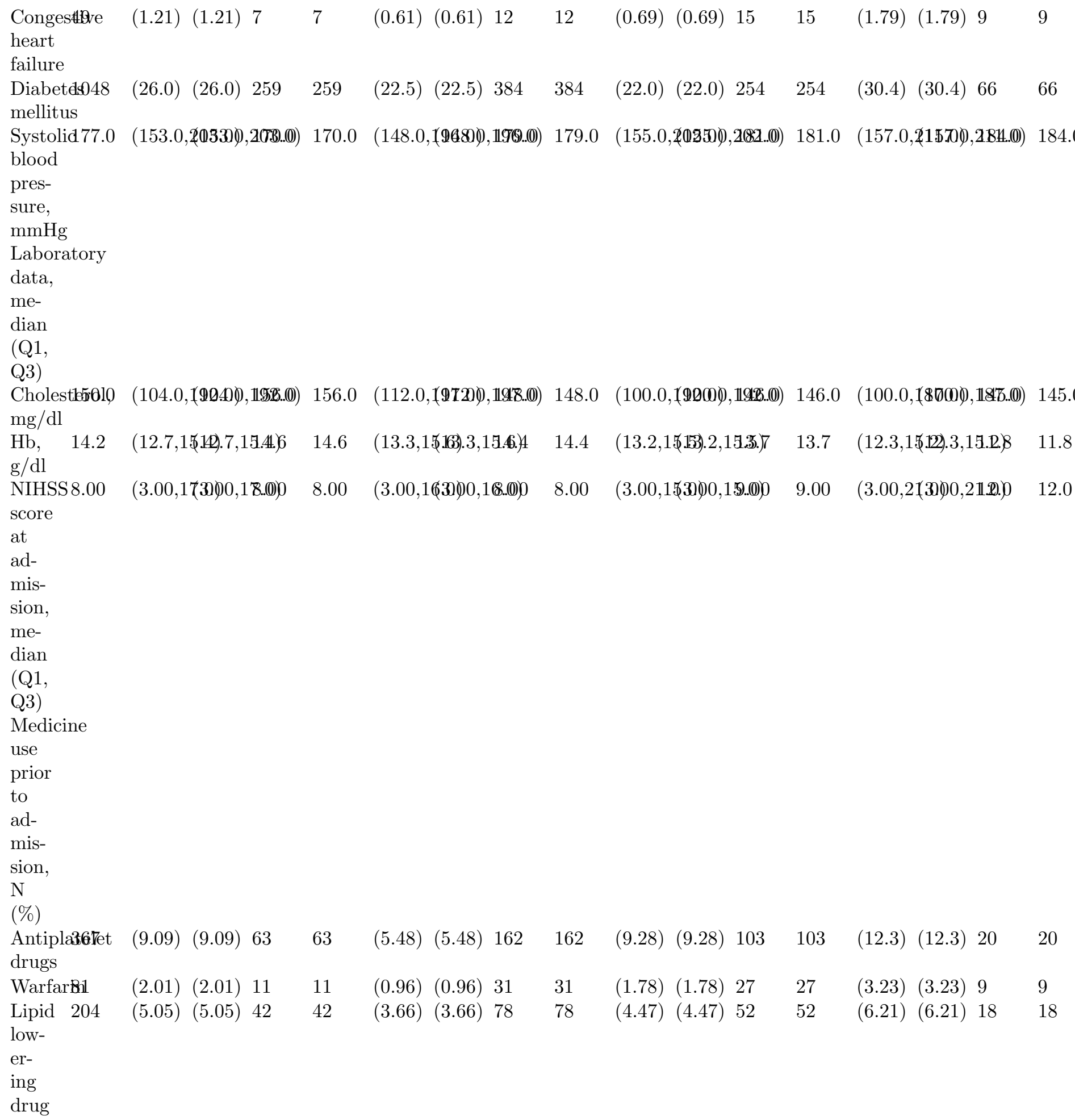


${ }^{*} \mathrm{Chi}-{ }^{*} \mathrm{Chi}-{ }^{*} \mathrm{Chi}-{ }^{*} \mathrm{Chi}-{ }^{*} \mathrm{Chi}-{ }^{*} \mathrm{Chi}-{ }^{*} \mathrm{Chi}-{ }^{*} \mathrm{Chi}-{ }^{*} \mathrm{Chi}-{ }^{*} \mathrm{Chi}-{ }^{*} \mathrm{Chi}-{ }^{*} \mathrm{Chi}-{ }^{*} \mathrm{Chi}-{ }^{*} \mathrm{Chi}-{ }^{*} \mathrm{Chi}-{ }^{*} \mathrm{Chi}-{ }^{*} \mathrm{Chi}-{ }^{*} \mathrm{Ch}$ square square square square square square square square square square square square square square square square square squa test, test, test, test, test, test, test, test, test, test, test, test, test, test, test, test, test, test, and and and and and and and and and and and and and and and and and and KruskaKruskaKruskaKruskaKruskaKruskaKruskaKruskaKruskaKruskaKruskaKruskaKruskaKruskaKruskaKruskaKruskaKru Wallis Wallis Wallis Wallis Wallis Wallis Wallis Wallis Wallis Wallis Wallis Wallis Wallis Wallis Wallis Wallis Wallis Wal test test test test test test test test test test test test test test test test test test eGFR, eGFR, eGFR, eGFR, eGFR, eGFR, eGFR, eGFR, eGFR, eGFR, eGFR, eGFR, eGFR, eGFR, eGFR, eGFR, eGFR, eGF es- $\quad$ es- $\quad$ es- $\quad$ es- $\quad$ es- es- es- es- es- es- es- es- es- es- es- es- es- esti- ti- ti- ti- ti- ti- ti- ti- ti- ti- ti- ti- ti- ti- ti- ti- ti- timated mated mated mated mated mated mated mated mated mated mated mated mated mated mated mated mated mat glomergłomerglomerglomergłomergłomergłomergłomergłomergłomergłomergłomergłomergłomerglomergłomergłomergłom $\begin{array}{lllllllllllllllllll}\text { lar } & \text { lar } & \text { lar } & \text { lar } & \text { lar } & \text { lar } & \text { lar } & \text { lar } & \text { lar } & \text { lar } & \text { lar } & \text { lar } & \text { lar } & \text { lar } & \text { lar } & \text { lar } & \text { lar } & \text { lar } \\ \text { fil- } & \text { fil- } & \text { fil- } & \text { fil- } & \text { fil- } & \text { fil- } & \text { fil- } & \text { fil- } & \text { fil- } & \text { fil- } & \text { fil- } & \text { fil- } & \text { fil- } & \text { fil- } & \text { fil- } & \text { fil- } & \text { fil- } & \text { fil- } \\ \text { tra- } & \text { tra- } & \text { tra- } & \text { tra- } & \text { tra- } & \text { tra- } & \text { tra- } & \text { tra- } & \text { tra- } & \text { tra- } & \text { tra- } & \text { tra- } & \text { tra- } & \text { tra- } & \text { tra- } & \text { tra- } & \text { tra- } & \text { tra- } \\ \text { tion } & \text { tion } & \text { tion } & \text { tion } & \text { tion } & \text { tion } & \text { tion } & \text { tion } & \text { tion } & \text { tion } & \text { tion } & \text { tion } & \text { tion } & \text { tion } & \text { tion } & \text { tion } & \text { tion } & \text { tion } \\ \text { rate; } & \text { rate; } & \text { rate; } & \text { rate; } & \text { rate; } & \text { rate; } & \text { rate; } & \text { rate; } & \text { rate; } & \text { rate; } & \text { rate; } & \text { rate; } & \text { rate; } & \text { rate; } & \text { rate; } & \text { rate; } & \text { rate; } & \text { rate } \\ \text { Q1, } & \text { Q1, } & \text { Q1, } & \text { Q1, } & \text { Q1, } & \text { Q1, } & \text { Q1, } & \text { Q1, } & \text { Q1, } & \text { Q1, } & \text { Q1, } & \text { Q1, } & \text { Q1, } & \text { Q1, } & \text { Q1, } & \text { Q1, } & \text { Q1, } & \text { Q1, } \\ 25 \text { th } & 25 \text { th } & 25 \text { th } & 25 \text { th } & 25 \text { th } & 25 \text { th } & 25 \text { th } & 25 \text { th } & 25 \text { th } & 25 \text { th } & 25 \text { th } & 25 \text { th } & 25 \text { th } & 25 \text { th } & 25 \text { th } & 25 \text { th } & 25 \text { th } & 25 \text { th } \\ \text { per- } & \text { per- } & \text { per- } & \text { per- } & \text { per- } & \text { per- } & \text { per- } & \text { per- } & \text { per- } & \text { per- } & \text { per- } & \text { per- } & \text { per- } & \text { per- } & \text { per- } & \text { per- } & \text { per- } & \text { per- }\end{array}$ centile;centile;centile;centile;centile;centile;centile;centile;centile;centile;centile;centile;centile;centile;centile;centile;centile;cent

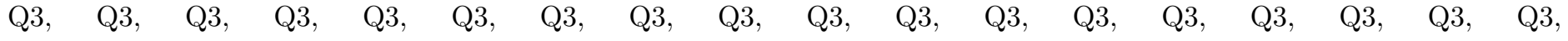
75th 75th 75th 75 th 75 th 75 th 75 th 75 th 75 th 75 th 75 th 75 th 75 th 75 th 75 th 75 th 75 th 75th per- per- per- per- per- per- per- per- per- per- per- per- per- per- per- per- per- percentile;centile;centile;centile;centile;centile;centile;centile;centile;centile;centile;centile;centile;centile;centile;centile;centile;cent $\mathrm{SD}, \quad \mathrm{SD}, \quad \mathrm{SD}, \quad \mathrm{SD}, \quad \mathrm{SD}, \quad \mathrm{SD}, \quad \mathrm{SD}, \quad \mathrm{SD}, \quad \mathrm{SD}, \quad \mathrm{SD}, \quad \mathrm{SD}, \quad \mathrm{SD}, \quad \mathrm{SD}, \quad \mathrm{SD}, \quad \mathrm{SD}, \quad \mathrm{SD}, \quad \mathrm{SD}, \quad \mathrm{SD}$, stan- stan- stan- stan- stan- stan- stan- stan- stan- stan- stan- stan- stan- stan- stan- stan- stan- stan dard dard dard dard dard dard dard dard dard dard dard dard dard dard dard dard dard dard de- de- de- de- de- de- de- de- de- de- de- de- de- de- de- de- de- devi- vi- vi- vi- vi- vi- vi- vi- vi- vi- vi- vi- vi- vi- vi- vi- vi-

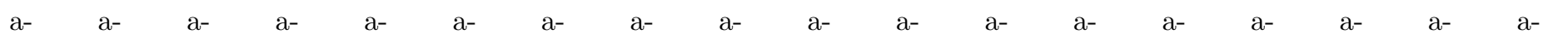
tion; tion; tion; tion; tion; tion; tion; tion; tion; tion; tion; tion; tion; tion; tion; tion; tion; tion BMI, BMI, BMI, BMI, BMI, BMI, BMI, BMI, BMI, BMI, BMI, BMI, BMI, BMI, BMI, BMI, BMI, BM! body body body body body body body body body body body body body body body body body bod. mass mass mass mass mass mass mass mass mass mass mass mass mass mass mass mass mass mas in- in- in- in- in- in- in- in- in- in- in- in- in- in- in- in- in- in-

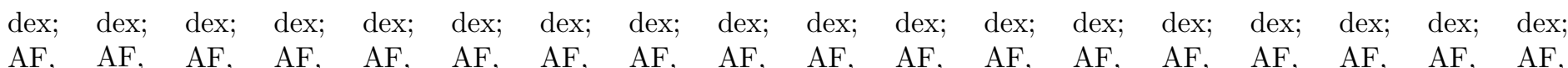
atrial atrial atrial atrial atrial atrial atrial atrial atrial AF, AF, AF, AF, AF, AF, AF, AF, AF, fib- fib- fib- fib- fib- fib- fib- fib- fib- fib- fib- fib- fib- fib- fib- fib- fib- fibril- ril- ril- ril- ril- ril- ril- ril- ril- ril- ril- ril- ril- ril- ril- ril- ril- rilla- la- la- la- la- la- la- la- la- la- la- la- la- la- la- la- la- lation; tion; tion; tion; tion; tion; tion; tion; tion; tion; tion; tion; tion; tion; tion; tion; tion; tion $\mathrm{Hb}, \mathrm{Hb}, \mathrm{Hb}, \mathrm{Hb}, \mathrm{Hb}, \mathrm{Hb}, \mathrm{Hb}, \mathrm{Hb}, \mathrm{Hb}, \mathrm{Hb}, \mathrm{Hb}, \mathrm{Hb}, \mathrm{Hb}, \mathrm{Hb}, \mathrm{Hb}, \mathrm{Hb}, \mathrm{Hb}, \mathrm{Hb}$

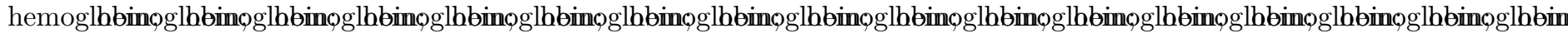
NIHSS,NIHSS,NIHSS,NIHSS,NIHSS,NIHSS,NIHSS,NIHSS,NIHSS,NIHSS,NIHSS,NIHSS,NIHSS,NIHSS,NIHSS,NIHSS,NIHSS,NIH Na- $\mathrm{Na}^{-} \mathrm{Na}-\mathrm{Na}-\mathrm{Na}-\mathrm{Na}-\mathrm{Na}-\mathrm{Na}-\mathrm{Na}-\mathrm{Na}-\mathrm{Na}-\mathrm{Na}-\mathrm{Na}-\mathrm{Na}-\mathrm{Na}-\mathrm{Na}-\mathrm{Na}-\mathrm{Na}-$ tional tional tional tional tional tional tional tional tional tional tional tional tional tional tional tional tional tion

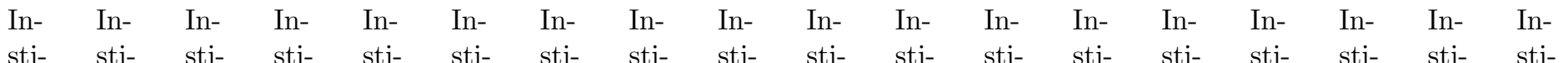
$\begin{array}{lllllllll} & \\ \text { tutes } & \text { tutes } & \text { tutes } & \text { tutes } & \text { tutes } & \text { tutes } & \text { tutes tutes tutes tutes tutes tutes tutes tutes tutes tutes tutes tute }\end{array}$ of of of of of of of of of of of of of of of of of of Stroke Stroke Stroke Stroke Stroke Stroke Stroke Stroke Stroke Stroke Stroke Stroke Stroke Stroke Stroke Stroke Stroke Stro Scale Scale Scale Scale Scale Scale Scale Scale Scale Scale Scale Scale Scale Scale Scale Scale Scale Scal 


\begin{tabular}{|c|c|c|c|c|c|}
\hline $\begin{array}{l}\text { Table } 2 . \\
\text { Incidence and } \\
\text { hazard ratios } \\
\text { of mortality at } \\
\text { one-month } \\
\text { after } \\
\text { intracerebral } \\
\text { hemorrhage by } \\
\text { eGFR levels at } \\
\text { admission }\end{array}$ & $\begin{array}{l}\text { Table } 2 . \\
\text { Incidence and } \\
\text { hazard ratios } \\
\text { of mortality at } \\
\text { one-month } \\
\text { after } \\
\text { intracerebral } \\
\text { hemorrhage by } \\
\text { eGFR levels at } \\
\text { admission } \\
\text { Mortality } \mathrm{N}=258\end{array}$ & $\begin{array}{l}\text { Table } 2 . \\
\text { Incidence and } \\
\text { hazard ratios } \\
\text { of mortality at } \\
\text { one-month } \\
\text { after } \\
\text { intracerebral } \\
\text { hemorrhage by } \\
\text { eGFR levels at } \\
\text { admission } \\
\text { Person-days }\end{array}$ & $\begin{array}{l}\text { Table } 2 . \\
\text { Incidence and } \\
\text { hazard ratios } \\
\text { of mortality at } \\
\text { one-month } \\
\text { after } \\
\text { intracerebral } \\
\text { hemorrhage by } \\
\text { eGFR levels at } \\
\text { admission } \\
\text { Rate }^{++}\end{array}$ & $\begin{array}{l}\text { Table } 2 . \\
\text { Incidence and } \\
\text { hazard ratios } \\
\text { of mortality at } \\
\text { one-month } \\
\text { after } \\
\text { intracerebral } \\
\text { hemorrhage by } \\
\text { eGFR levels at } \\
\text { admission } \\
\text { Crude HR (95\% } \\
\text { CI) }\end{array}$ & $\begin{array}{l}\text { Table } 2 . \\
\text { Incidence and } \\
\text { hazard ratios } \\
\text { of mortality at } \\
\text { one-month } \\
\text { after } \\
\text { intracerebral } \\
\text { hemorrhage by } \\
\text { eGFR levels at } \\
\text { admission } \\
\text { Adjusted HR } \\
(95 \% \mathrm{CI})^{\mathrm{a}}\end{array}$ \\
\hline $\begin{array}{l}\mathrm{eGFR} \\
\mathrm{mL} / \mathrm{min} / 1.73 \mathrm{~m}^{2}\end{array}$ & $\mathrm{n}$ & & & & \\
\hline [?] 90 & 43 & 28667 & 1.50 & 1.00 & 1.00 \\
\hline $60-89$ & 93 & 43836 & 2.12 & $1.42(0.89,2.04)$ & $1.54(1.05,2.27)^{*}$ \\
\hline $30-59$ & 74 & 20265 & 3.65 & $\begin{array}{l}2.42(1.66 \\
3.53)^{* *}\end{array}$ & $\begin{array}{l}2.24(1.48 \\
3.38)^{* * *}\end{array}$ \\
\hline $15-29$ & 16 & 3332 & 4.80 & $\begin{array}{l}3.22(1.81 \\
5.71)^{* *}\end{array}$ & $2.22(1.20,4.12)^{*}$ \\
\hline$<15$ or dialysis & 32 & 3849 & 8.31 & $\begin{array}{l}5.40(3.42 \\
8.54)^{* *}\end{array}$ & $\begin{array}{l}4.59(2.71 \\
7.78)^{* * *}\end{array}$ \\
\hline $\mathrm{P}$ for trend & & & $<0.001$ & $<0.001$ & $<0.001$ \\
\hline
\end{tabular}




\begin{tabular}{|c|c|c|c|c|c|}
\hline${ }^{++}$per 1000 & ${ }^{++}$per 1000 & ${ }^{++}$per 1000 & ${ }^{++}$per 1000 & ${ }^{++}$per 1000 & ${ }^{++}$per 1000 \\
\hline person-days & person-days & person-days & person-days & person-days & person-days \\
\hline${ }^{\mathrm{a}}$ Adjusted for & ${ }^{a}$ Adjusted for & ${ }^{a}$ Adjusted for & ${ }^{a}$ Adjusted for & a Adjusted for & ${ }^{a}$ Adjusted for \\
\hline age, gender, & age, gender, & age, gender, & age, gender, & age, gender, & age, gender, \\
\hline body mass & body mass & body mass & body mass & body mass & body mass \\
\hline index, & index, & index, & index, & index, & index, \\
\hline smoking, & smoking, & smoking, & smoking, & smoking, & smoking, \\
\hline etiology of & etiology of & etiology of & etiology of & etiology of & etiology of \\
\hline intracerebral & intracerebral & intracerebral & intracerebral & intracerebral & intracerebral \\
\hline hemorrhage, & hemorrhage, & hemorrhage, & hemorrhage, & hemorrhage, & hemorrhage, \\
\hline $\begin{array}{l}\text { hypertension, } \\
\text { atrial }\end{array}$ & $\begin{array}{l}\text { hypertension, } \\
\text { atrial }\end{array}$ & $\begin{array}{l}\text { hypertension, } \\
\text { atrial }\end{array}$ & $\begin{array}{l}\text { hypertension, } \\
\text { atrial }\end{array}$ & $\begin{array}{l}\text { hypertension, } \\
\text { atrial }\end{array}$ & $\begin{array}{l}\text { hypertension, } \\
\text { atrial }\end{array}$ \\
\hline fibrillation, & fibrillation, & fibrillation, & fibrillation, & fibrillation, & fibrillation, \\
\hline previous & previous & previous & previous & previous & previous \\
\hline stroke history, & stroke history, & stroke history, & stroke history, & stroke history, & stroke history, \\
\hline ischemic heart & ischemic heart & ischemic heart & ischemic heart & ischemic heart & ischemic heart \\
\hline disease, & disease, & disease, & disease, & disease, & disease, \\
\hline congestive & congestive & congestive & congestive & congestive & congestive \\
\hline $\begin{array}{l}\text { heart failure, } \\
\text { diabetes }\end{array}$ & $\begin{array}{l}\text { heart failure, } \\
\text { diabetes }\end{array}$ & $\begin{array}{l}\text { heart failure, } \\
\text { diabetes }\end{array}$ & $\begin{array}{l}\text { heart failure, } \\
\text { diabetes }\end{array}$ & $\begin{array}{l}\text { heart failure, } \\
\text { diabetes }\end{array}$ & $\begin{array}{l}\text { heart failure, } \\
\text { diabetes }\end{array}$ \\
\hline mellitus, & mellitus, & mellitus, & mellitus, & mellitus, & mellitus, \\
\hline systolic blood & systolic blood & systolic blood & systolic blood & systolic blood & systolic blood \\
\hline pressure, & pressure, & pressure, & pressure, & pressure, & pressure, \\
\hline hemoglobin, & hemoglobin, & hemoglobin, & hemoglobin, & hemoglobin, & hemoglobin, \\
\hline cholesterol, & cholesterol, & cholesterol, & cholesterol, & cholesterol, & cholesterol, \\
\hline NIHSS score & NIHSS score & NIHSS score & NIHSS score & NIHSS score & NIHSS score \\
\hline at admission & at admission & at admission & at admission & at admission & at admission \\
\hline and medicine & and medicine & and medicine & and medicine & and medicine & and medicine \\
\hline use prior to & use prior to & use prior to & use prior to & use prior to & use prior to \\
\hline $\operatorname{admission} * \mathrm{p}$ & $\operatorname{admission} * \mathrm{p}$ & $\operatorname{admission} * p$ & $\operatorname{admission} * \mathrm{p}$ & $\operatorname{admission} * \mathrm{p}$ & $\operatorname{admission} * \mathrm{p}$ \\
\hline$<0.01,{ }^{* *} \mathrm{p}$ & $<0.01,{ }^{* *} \mathrm{p}$ & $<0.01,{ }^{* *} \mathrm{p}$ & $<0.01,{ }^{* *} \mathrm{p}$ & $<0.01,{ }^{* *} \mathrm{p}$ & $<0.01,{ }^{* *} \mathrm{p}$ \\
\hline$<0.001$ & $<0.001$ & $<0.001$ & $<0.001$ & $<0.001$ & $<0.001$ \\
\hline Table 3. & Table 3. & Table 3. & Table 3. & Table 3. & Table 3. \\
\hline Incidence and & Incidence and & Incidence and & Incidence and & Incidence and & Incidence and \\
\hline hazard ratios & hazard ratios & hazard ratios & hazard ratios & hazard ratios & hazard ratios \\
\hline of mortality at & of mortality at & of mortality at & of mortality at & of mortality at & of mortality at \\
\hline one year after & one year after & one year after & one year after & one year after & one year after \\
\hline intracerebral & intracerebral & intracerebral & intracerebral & intracerebral & intracerebral \\
\hline hemorrhage by & hemorrhage by & hemorrhage by & hemorrhage by & hemorrhage by & hemorrhage by \\
\hline $\begin{array}{l}\text { eGFR level at } \\
\text { admission }\end{array}$ & $\begin{array}{l}\text { eGFR level at } \\
\text { admission }\end{array}$ & $\begin{array}{l}\text { eGFR level at } \\
\text { admission }\end{array}$ & $\begin{array}{l}\text { eGFR level at } \\
\text { admission }\end{array}$ & $\begin{array}{l}\text { eGFR level at } \\
\text { admission }\end{array}$ & $\begin{array}{l}\text { eGFR level at } \\
\text { admission }\end{array}$ \\
\hline & Mortality $\mathrm{N}=394$ & Person-days & Rate $^{++}$ & Crude HR $(95 \%$ & Adjusted HR \\
\hline & & & & CI) & $(95 \% \mathrm{CI})^{\mathrm{a}}$ \\
\hline \multicolumn{6}{|l|}{ eGFR } \\
\hline \multicolumn{6}{|l|}{$\mathrm{mL} / \mathrm{min} / 1.73$} \\
\hline \multicolumn{6}{|l|}{$\mathrm{m}^{2}$} \\
\hline [?] 90 & 59 & 187392 & 0.31 & 1.00 & 1.00 \\
\hline $60-89$ & 139 & 299308 & 0.46 & $1.52(1.12,2.06)^{*}$ & $1.49(1.08,2.04)^{*}$ \\
\hline $30-59$ & 112 & 134013 & 0.84 & $\begin{array}{l}2.66(1.94 \\
3.65)^{* *}\end{array}$ & $\begin{array}{l}2.06(1.47 \\
2.89)^{* * *}\end{array}$ \\
\hline
\end{tabular}


15-29

$<15$ or dialysis

$\mathrm{P}$ for trend

${ }^{++}$per 1000

person-days

${ }^{a}$ Adjusted for

age, gender,

body mass

index,

smoking,

etiology of

intracerebral

hemorrhage,

hypertension,

atrial

fibrillation,

previous

stroke history,

ischemic heart

disease,

congestive

heart failure,

diabetes

mellitus,

systolic blood

pressure,

hemoglobin,

cholesterol,

NIHSS score

at admission

and medicine

use ${ }^{*} \mathrm{p}<0.01$,

$* * \mathrm{p}<0.001$
50

34

${ }^{++}$per 1000

person-days

${ }^{a}$ Adjusted for

age, gender,

body mass

index,

smoking,

etiology of

intracerebral

hemorrhage,

hypertension,

atrial

fibrillation,

previous

stroke history,

ischemic heart

disease,

congestive

heart failure,

diabetes

mellitus,

systolic blood

pressure,

hemoglobin,

cholesterol,

NIHSS score

at admission

and medicine

use ${ }^{*} \mathrm{p}<0.01$,

$* *$ p $<0.001$
21375

19728

${ }^{++}$per 1000

person-days

${ }^{a}$ Adjusted for

age, gender,

body mass

index,

smoking,

etiology of

intracerebral

hemorrhage,

hypertension,

atrial

fibrillation,

previous

stroke history,

ischemic heart

disease,

congestive

heart failure,

diabetes

mellitus,

systolic blood

pressure,

hemoglobin,

cholesterol,

NIHSS score

at admission

and medicine

use ${ }^{*} \mathrm{p}<0.01$,

$* * \mathrm{p}<0.001$
1.72

2.34

$<0.001$

${ }^{++}$per 1000

person-days

${ }^{a}$ Adjusted for

age, gender,

body mass

index,

smoking,

etiology of

intracerebral

hemorrhage,

hypertension,

atrial

fibrillation,

previous

stroke history,

ischemic heart

disease,

congestive

heart failure,

diabetes

mellitus,

systolic blood

pressure,

hemoglobin,

cholesterol,

NIHSS score

at admission

and medicine

use ${ }^{*} \mathrm{p}<0.01$,

$* * \mathrm{p}<0.001$
5.12(3.36,

$7.81)^{* *}$

6.48(4.44,

$9.44)^{* *}$

$<0.001$

${ }^{++}$per 1000

person-days

${ }^{a}$ Adjusted for

age, gender,

body mass

index,

smoking,

etiology of

intracerebral

hemorrhage,

hypertension,

atrial

fibrillation,

previous

stroke history,

ischemic heart

disease,

congestive

heart failure,

diabetes

mellitus,

systolic blood

pressure,

hemoglobin,

cholesterol,

NIHSS score

at admission

and medicine

use ${ }^{*} \mathrm{p}<0.01$,

$* * \mathrm{p}<0.001$
3.02(1.91,

$4.77)^{* * *}$

4.54(2.95,

$6.98)^{* * *}$

$<0.001$

${ }^{++}$per 1000

person-days

${ }^{a}$ Adjusted for

age, gender,

body mass

index,

smoking,

etiology of

intracerebral

hemorrhage,

hypertension,

atrial

fibrillation,

previous

stroke history,

ischemic heart

disease,

congestive

heart failure,

diabetes

mellitus,

systolic blood

pressure,

hemoglobin,

cholesterol,

NIHSS score

at admission

and medicine

use *p $<0.01$,

$* * \mathrm{p}<0.001$

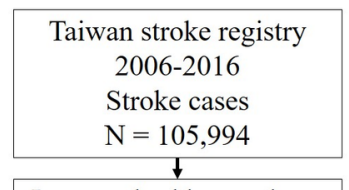

Intracerebral hemorrhage

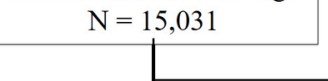

Intracerebral hemorrhage $\mathrm{N}=4,036$
Exclusion: age under 18 years $(\mathrm{N}=111)$, and missing data of dialysis status, body mass

index, systolic blood pressure, hemoglobin,

serum cholesterol, or serum creatinine $(\mathrm{N}=$ 10,884)

\begin{tabular}{|c|c|c|c|c|c|}
\hline \multicolumn{1}{|c|}{$\begin{array}{c}\mathrm{e} G F R \geq 90 \\
\mathrm{~mL} / \mathrm{min} / 1.73 \mathrm{~m}^{2} \\
\mathrm{~N}=1,149\end{array}$} & $\begin{array}{c}\mathrm{eGFR} 60-89 \\
\mathrm{~mL} / \mathrm{min} / 1.73 \mathrm{~m}^{2} \\
\mathrm{~N}=1,746\end{array}$ & $\begin{array}{c}\mathrm{eGFR} 30-59 \\
\mathrm{~mL} / \mathrm{min} / 1.73 \mathrm{~m}^{2} \\
\mathrm{~N}=837\end{array}$ & $\begin{array}{c}\mathrm{eGFR} 15-29 \\
\mathrm{~mL} / \mathrm{min} / 1.73 \mathrm{~m}^{2} \\
\mathrm{~N}=135\end{array}$ & $\begin{array}{c}\mathrm{eGFR}<15 \\
\mathrm{~mL} / \mathrm{min} / 1.73 \mathrm{~m}^{2} \\
\text { or dialysis } \\
\mathrm{N}=169\end{array}$ \\
\end{tabular}



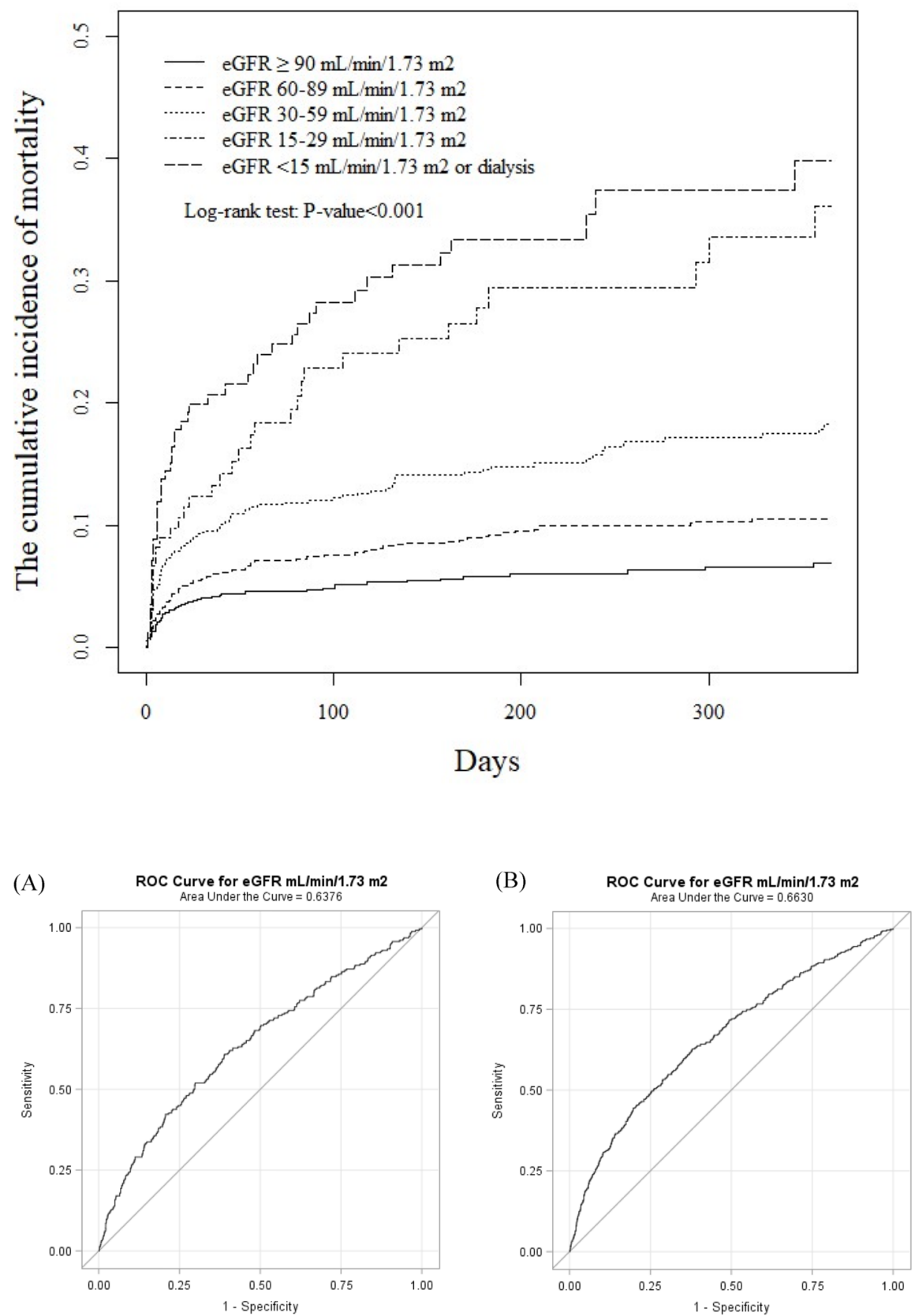